\title{
Development of an on-line management information system for community mental health centers
}

\author{
KENNETH E. HANSEN, JAMES H. JOHNSON, and THOMAS A. WILLIAMS \\ Veterans Administration Hospital, Salt Lake City, Utah 84148, and University of Utah College of \\ Medicine, Salt Lake City, Utah 84148
}

\begin{abstract}
An on-line computerized management information system has been developed at the Salt Lake City VA Hospital and is currently being implemented at Salt Lake Community Mental Health Center. An introduction to this system, including systems design and procedures for development, are presented. The advantages of on-line technology as compared to batch processing technology are also discussed.
\end{abstract}

The degree of success attained by an organization is directly related to the decision making acumen of its administrators. An advantageous decision is more probable when an administrator has ready access to that information which relates both directly and indirectly to that decision. The multiplicity of decisions which face any administrator requires that a wide variety of data be collected and maintained by the various operations within an organization. Furthermore, the data must be readily accessible and easily aggregated into appropriate formats, so that the possible implications of alternative decisions can be examined.

Management information systems (MIS) have been widely implemented in business settings as a systematic approach to collecting and reporting the information necessary for decision making. In recent years, attempts have been made to apply these concepts to mental health care delivery systems. In several ways, the components of a community mental health center (CMHC) are analogous to the components of a business structure, so that a cross-fertilization of techniques may take place. Both seek effective utilization of resources. Both must achieve effective resource utilization to continue to exist. And finally, both must meet the needs of consumers and stockholders (taxpayers). However, there are also differences between a CMHC and a business. For example, in a CMHC, information needs are very broad and include both administrators and researchers. Thus, a direct application of corporate management techniques to a mental health delivery system is not feasible.

In recent years, various management information systems have been developed and implemented by mental health centers. Many of these systems are constructed from a combination of transaction processing and data base management techniques. A few systems (Elpers \& Chapman, 1973; Kaplan \& Smith, 1974; Kurke \& Van Houdnos, 1974; Broskowski, Note 1) have been automated by means of electronic data-processing equipment. Several fundamentals for systems design have been learned in the process. First, the methods of data collection must be uncomplicated. All data-collection documents should be designed with the user in mind. Forms design should be simple, yet it should allow for the collection of all necessary data and be susceptible to modification. Routine data gathering should be maximized for clerical staff and minimized for clinical staff. Report generation should be timely and relevant to the needs of the individual mental health center. Reports should meet the needs of management, research, clinical activities, and funding agencies. Finally, the system must insure confidentiality of patient records. An awareness of these fundamentals is a necessary precursor for the appropriate systems design of an MIS.

A comprehensive, on-line computerized MIS has been designed and is currently being implemented at the Salt Lake Community Mental Health Center. This MIS is a functional subset of the on-line psychiatric assessment system developed in cooperation between the College of Medicine of the University of Utah and the Salt Lake City VA Hospital (Johnson, Giannetti, \& Williams, 1975; Johnson \& Williams, 1975; Williams, Johnson, \& Bliss, 1975). Thus, the Utah system now provides a management information system as well as psychiatric assessment services. The purpose of this paper is to describe the systems design and development of this on-line management information system.

\section{FUNCTIONAL DESIGN}

While the majority of clinical services rendered by the center are on an outpatient basis, the center also maintains several other service units including inpatient, partial hospitalization, children's behavior therapy, and crisis intervention. Other functions of the center include consultation, training, and research. With this wide variety of services, the first step in systems design was to determine the needs of each functional unit. The analysis of how to fulfill these various needs 
provided the functional specifications for data collection.

One of our initial design tasks was the development of a uniform method of data collection. This required a synthesis of data-collection specifications for each of several functions within the center. Out of this analysis, three basic documents and several ancillary forms were developed to collect all necessary input data. The first basic document is the admissions form, which is completed by an intake worker when a prospective client applies for services. This form is used to collect demographic, historical, and billing information. Once a client has been admitted for treatment, the admission form is used to change or update information about the patient. The second basic document is the termination form. A therapist completes this form when a client exits from treatment. Data for outcome and follow-up studies are provided by this document. The final basic document is the day activity record. This form is completed by staff members to record services performed and to act as a record of time deployment. The day activity record form is shown in Figure 1 as an example of input document design.

The Salt Lake Community Mental Health Center has a cathode-ray tube terminal (CRT) and an electrostatic printer which are connected via telephone lines to the computer at the VA Hospital. Data from all of the documents are typed directly into the CRT by the clerical staff.

Report generation is accomplished using a flexible process. Reports may be produced at any time during normal business hours and report content may be comprised of any of the variables in the data base. Certain reports, including mandatory reports for federal, state, and county agencies, are automatically generated at fixed intervals. Management reports about caseload, services rendered, costs of services, number of contacts, and patient characteristics are produced periodically in three levels. The first level is a cumulative report based on the entire mental health center. Level 2 reports describe the individual service units which comprise the center. The last level consists of individual staff reports. Any staff member may select additional reports of his own design to supplement all other output received. The individual staff report is shown in Figure 2, as an example of the kind of reports generated.

The MIS will also reduce much of the burden placed on clerical staff. Monthly patient billing statements, staff payroll listings, financial reports, and other timeconsuming processes are basic to this system. Certain information, such as budgetary and caseload data, is updated and remains on-line for constant monitoring.

A user is not authorized to access any of the MIS programs until a set of security codes, which are changed periodically, are entered correctly into the terminal. These codes are compared internally to a set of codes stored for the terminal being used. Thus, the appropriate codes must be submitted on a specific terminal before the user may proceed. All patient data are stored off-line on magnetic tapes which must be mounted by the computer operator. Therefore, access to patient data is only possible during normal business hours.

\section{BASIC SYSTEM}

The software configuration consists of a terminal control program which is resident in the foreground (real-time) partition of memory and has the capability of controlling 32 terminals in a time-sharing environment. The average response time on each terminal is less than $1 \mathrm{sec}$. The terminal control program is comprised of several different modules, including a file manager, report generator (Johnson, Cole, \& Williams, 1975), an on-line editor, and a NORDIC interpreter (Hansen, Note 2). NORDIC is a user-oriented language in which all the data-collection programs are written. For a detailed hardware configuration of the system, see Cole, Johnson, and Williams (1975).

All data collected through the terminal control program are stored sequentially on disk files until data is completed for the day. At this point, an update program is initiated in batch mode which produces a trailing audit and summary of the day's transactions. The data are then sorted and merged into a master tape file which is stored off-line with backup. The master file is segmented into the patient file, staff file, and financial file, each of which contains a series of records in a linked allocation structure (Knuth, 1973). This type of record structure is advantageous for editing, since it eliminates all searches for specific items. Thus, addition or deletion of items is simplified. Upon completion of the master file merge, the report preparation program determines if any reports were requested. The update/merge processes are always completed before report generation proceeds, to insure that the data base is current. If a report has been requested, the report preparation program initiates the transfer of the master file to on-line status on directaccess disk storage. Master file data are then stored in an inverted file structure for rapid and efficient crosstabulation of variables. The report generator then produces the specified reports.

The system is designed around the user. CRT operators do not need knowledge of programming or computers. Menus of input options and possible reports are presented on the CRT and all steps in between are completely transparent to the user. All programs were designed and written utilizing techniques of structured programming accompanied with detailed documentation for ease of installation, operation, and maintenance.

The overall philosophy of the software development was to create a system that was inherently flexible and susceptible to change. The major emphasis was placed on methodology rather than initial content. This design 


\section{SPII IAINE TIETITAI MERITH}

STAFF NAME:

STAFF I.D. NUMBER: \begin{tabular}{|l|l|l|l|l|}
\hline & & & & $\square$ \\
\hline
\end{tabular}

DAY:

UNIT I.D. NUMBER

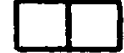

DATE: $\square / \square, \square$

CLIENT'S NAME OR EVENT

CLIENT SOCIAL SECURITY NO.

APPT

\begin{tabular}{|l|l|}
\hline MOOALITY ACTIVITY & \\
\hline
\end{tabular}

SPECIAL AREAS OF coucenin \begin{tabular}{l|l|l}
\hline APPT. & TIME & NUMAER \\
STATUS & SPENT \\
& PEOPLE \\
hr. min. & SERVED
\end{tabular}

2.

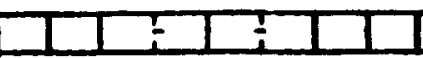

3

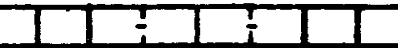

4

5

a
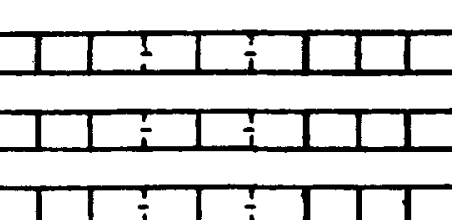

$\left[\begin{array}{c}1 \\ 1 \\ 1 \\ 1\end{array}\right.$

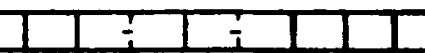

2
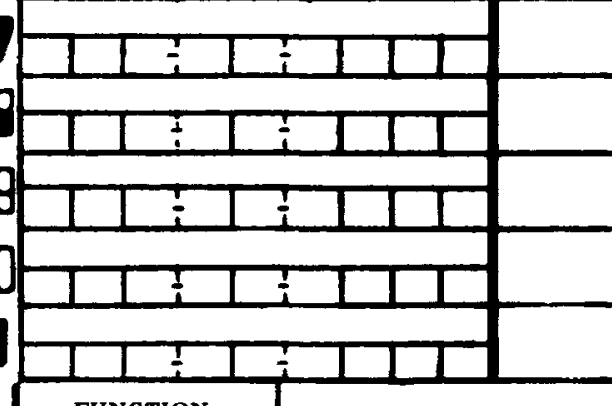

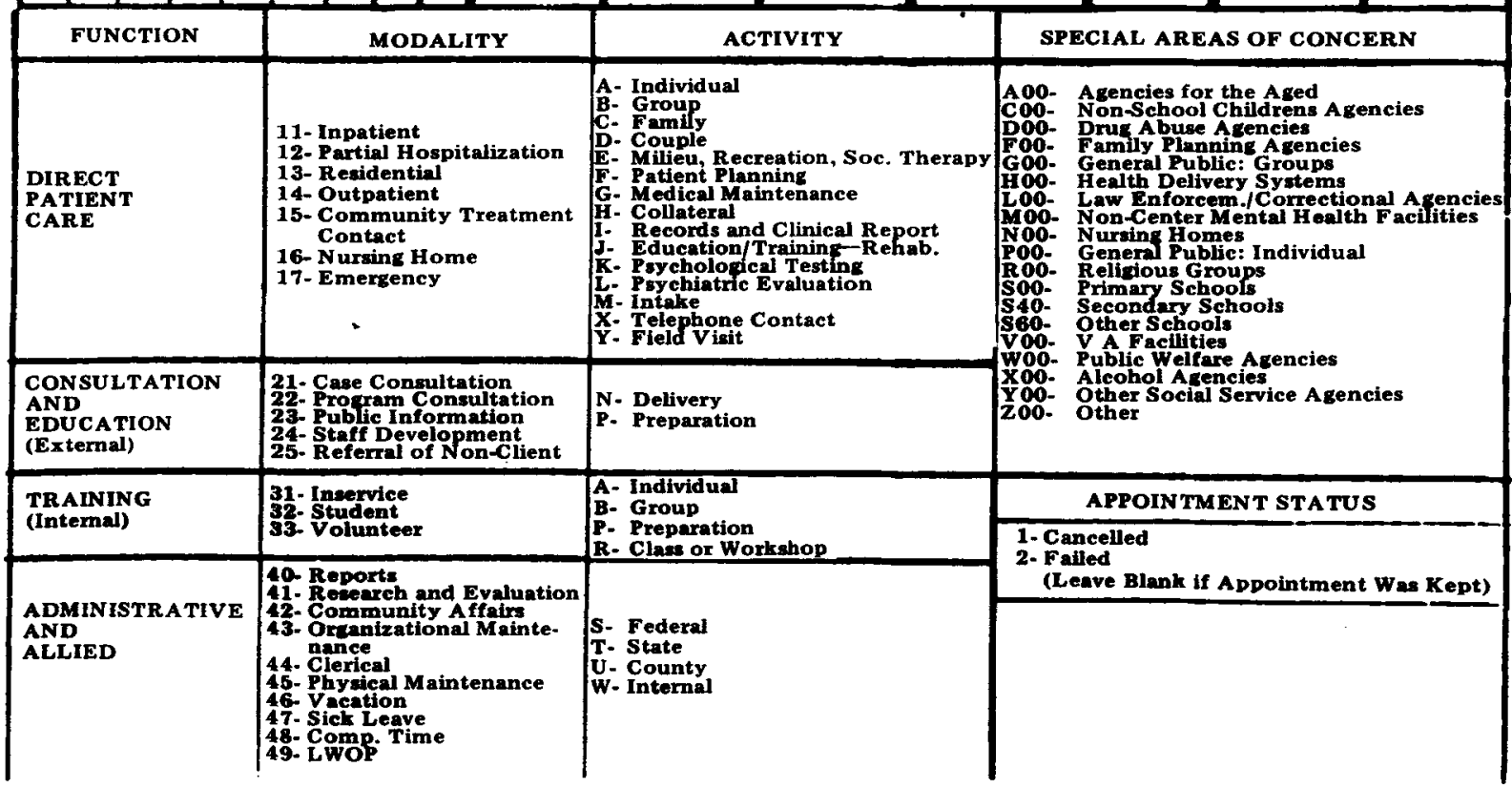

Figure 1. An example of data-collection forms: Day activity record. 


\section{OIRECT PATIENT CARE REPORT}

STAFF MEMEER: 03056 JONES,NANCY

PEAIODI 03/01/76 - 04/01/76

MODALITYI OUTPATIENT

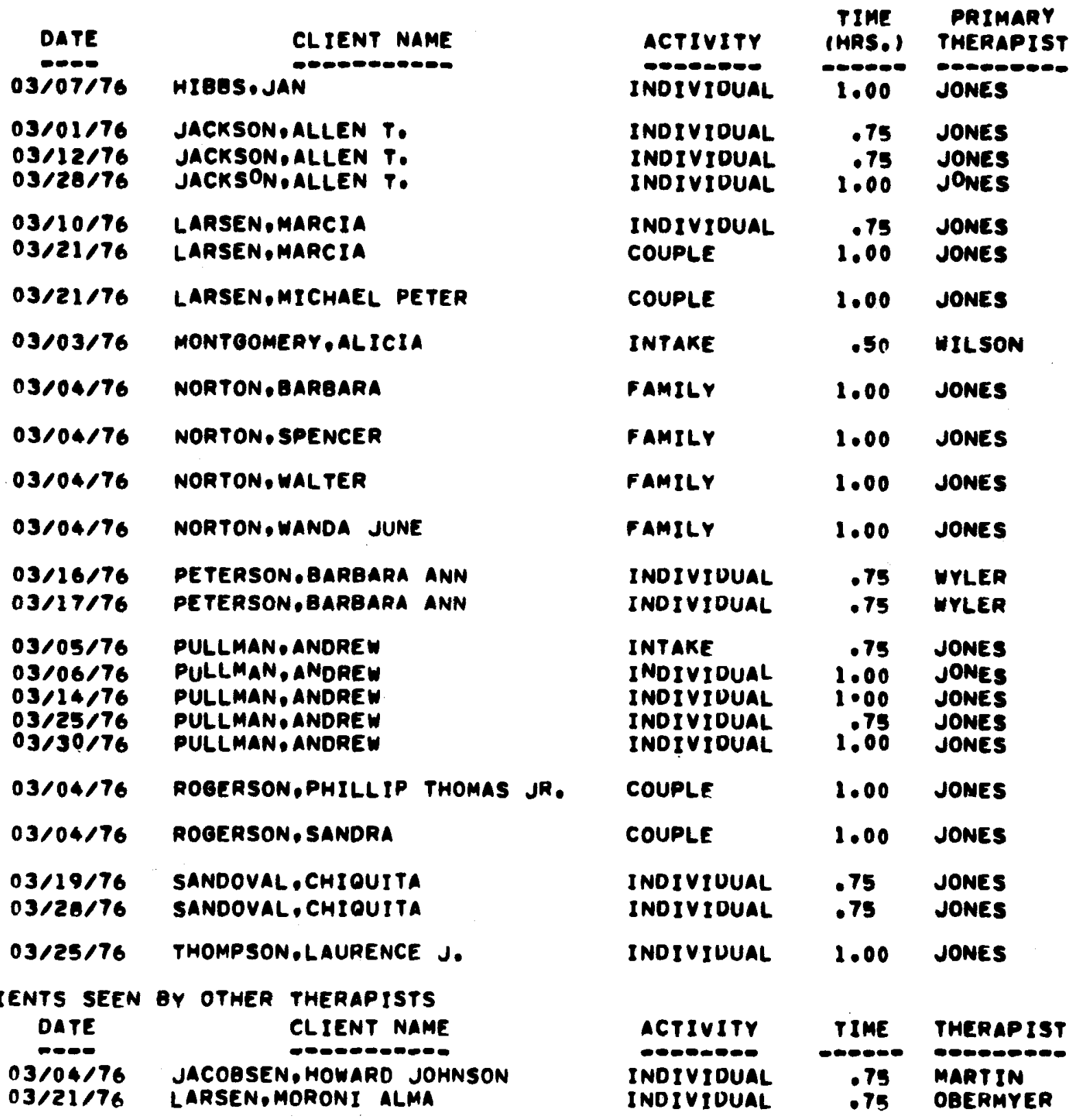

ELIENTS NOT SEEN THIS PERIOO
CLIENT
LAST SEEN
COIENT
- O-0MO-OD
$02 / 30 / 76$
$01 / 20 / 76$

BALLANTINE OARNOLD

SANCHEZ,LOUIS

Figure 2. An example of report format: Individual staff report. 
facilitates the evolution of a more complete information system as users require more data from the system.

\section{DISCUSSION}

The use of management information systems in mental health care centers is still a relatively new process. Therefore, it is expected that changes to the system will occur with future experience. The inherent flexibility of the Utah system allows it to change with the changing needs of the center. The installation of this system does not impose unnecessary constraints on the treatment staff. On the contrary, the MIS supplies staff members with valuable data to aid in managing caseloads in a more effective and efficient manner.

The gradual reduction of federal funding necessitates that mental health centers generate income from a variety of new sources, and, at the same time, become more efficient in their operation. A greater amount of third-party payments, consultation payments, and education program payments thus need to be collected. With the MIS system, these collections are more likely because adequate information about services rendered is gathered automatically. Better utilization of volunteer programs is an example of how centers can operate more effectively. With the Utah MIS, staff members have the resources to write interactive training programs to be presented to volunteers by the CRT. This allows faster volunteer training, thus allowing the volunteers to become involved with the center more effectively and efficiently.

The large data base that is produced by this system will provide a great deal of data for research. Studies are possible on patient characteristics in relation to treatment processes and outcome. Evaluation of processes will become a routine activity rather than an infrequent project.

The utilization of on-line technology offers several advantages over a batch processing mode. First, it eliminates the necessity for keypunching/verification of data from forms. Second, the turnaround time for report generation is greatly reduced. Third, it increases the user's flexibility in interacting with the system to provide information for nonroutine requirements. Finally, many manual processes are eliminated, thus reducing the possibilities of human error.

On-line systems are often thought to be prohibitively expensive. The reason for this lies in one-time hardware costs, such as terminals, direct-access storage media, and other specialized equipment. This system is designed so that the majority of data are stored off-line and transferred on-line only as needed, drastically reducing costs. An on-line system also obviates the need for data preparation; thus, additional savings are accrued. The cost of this system is less than $1 \%$ of the Salt Lake Community Mental Health Center's annual budget. This is more than justified by the benefits produced.

\section{REFERENCE NOTES}

1. Broskowski, A. Outline for MIS development. Workshop on Management Information Systems, University of Utah, 1975.

2. Hansen, K. E. Nordic-Numerically ordered response directed information collector. Unpublished manuscript. Systems and Evaluation Unit, Veterans Administration Hospital, Salt Lake City, Utah, 1976.

\section{REFERENCES}

Cole, E. B., Johnson, J. H., \& Willrams, T. A. Design considerations for an on-line computer system for automated psychiatric assessment. Behavior Research Methods \& Instrumentation, 1975, 7, 195-198.

ElPERS, J. R., \& ChAPMAN, R. L. Management information for mental health services. Administration in Mental Health, $1973,12-25$.

Johnson, J. H., Cole, E. B., \& Whliams, T. A. PROSE: A simple user-oriented program for computer-constructed narratives. Behavior Research Methods \& Instrumentation, 1975, 7, 309-310.

Johnson, J. H., Ginnnetti, R. A., \& Williams, T. A. Realtime psychological assessment and evaluation of psychiatric patients. Behavior Research Methods \& Instrumentation, $1975,7,199-200$.

Johnson, J. H., \& Williams, T. A. The use of on-line computer technology in a mental health admitting system. American Psychologist, 1975, 30, 388-390.

Kaplan, J. M., \& SMTtr, W. G. An evaluation program for a regional mental health center. In J. L. Crawford, D. W. Morgan, \& D. T. Gianturco (Eds.), Progress in mental health information systems: Computer applications. Cambridge, Mass: Ballinger, 1974.

KNUTH, D. E. Fundamental algorithms (2nd Ed.). Reading, Mass: Addison-Wesley, 1973.

KuRke, L., \& VAN HoudNos, H. Staff activity reporting: From the bottom up. In J. L. Crawford, D. W. Morgan, \& D. T. Gianturco (Eds.), Progress in mental health information systems: Computer applications. Cambridge, Mass: Ballinger, 1974.

Williams, T. A., Johnson, J. H., \& Bliss, E. L. A computer-assisted psychiatric assessment unit. American Journal of Psychiatry, 1975, 132, 1074-1076. 